\title{
Análisis comparativo de los sistemas de justicia administrativa en América Latina
}

\author{
Comparative Analysis of Administrative Justice Systems \\ in Latin America \\ Análise comparativa dos sistemas de justiça administrativa \\ na América Latina
}

RicARdo PERLINGEIRO*

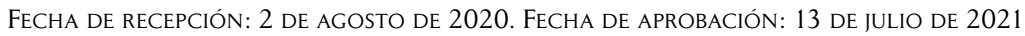

Doi: https://doi.org/10.12804/revistas.urosario.edu.co/sociojuridicos/a.10825

Para citar este artículo: Pelingeiro, R. (2022). Análisis comparativo de los sistemas de justicia administrativa en América Latina. Estudios Socio-Jurídicos, 24(1), 233-266. https://doi.org/10.12804/revistas.urosario.edu.co/ sociojuridicos/a.10825

\section{RESUMEN}

El presente ensayo consiste en un análisis comparativo respecto a las tradiciones de derecho administrativo en América Latina, y su impacto en el escenario contemporáneo, al igual que sobre las tendencias en las orientaciones generales de sus sistemas de justicia administrativa. El método que se sigue consiste en señalar las atribuciones de las autoridades administrativas y tratar de identificar la distinción, en América Latina, entre la 'función administrativa de implementación' (administrative function of implementation), el 'control de la legalidad de las decisiones administrativas' (no relacionado con función jurisdiccional alguna) y la 'protección de derechos' (por medio de una función jurisdiccional), mientras examinamos su génesis histórica y sus tendencias futuras. En esta perspectiva, el texto aborda los poderes administrativos y sus límites; las prerrogativas e instrumentos de las autoridades en el ejercicio de sus funciones de aplicación; el control de las decisiones administrativas por las propias autoridades administrativas y también por órganos externos, así como la protección judicial y extrajudicial de derechos frente a decisiones administrativas.

Palabras clave: América Latina; derecho comparado; justicia administrativa; tribunales.

* Profesor catedrático de la Facultad de Derecho de la UFF; profesor del programa de posgrado en Derecho (maestría y doctorado) de la Universidade Estácio de Sá; juez federal del Tribunal Regional Federal de la $2^{a}$ Región. Correo electrónico: ricardoperlingeiro@id.uff.br ORCID: https://orcid.org/0000-0002-6504-0594 


\section{ABSTRACT}

This article presents a comparative analysis regarding the traditions of administrative law in Latin America and their impact on the contemporary scene, as well as on the trends in the general orientations of their administrative justice systems. The method followed consists of pointing out the attributions of the administrative authorities and trying to identify the distinction, in Latin America, between the 'administrative function of implementation', the 'control of the legality of administrative decisions' (not related to any adjudication function), and the 'protection of rights' (by means of an adjudication function) while examining their historical genesis and future trends. In this perspective, the text addresses administrative powers and their limits: the prerogatives and instruments of the authorities in the exercise of their enforcement functions, the control of administrative decisions by the administrative authorities themselves and by external bodies, and the judicial and extrajudicial protection of rights against administrative decisions.

Keywords: Latin America; comparative law; administrative justice; courts.

\section{RESUMO}

Este ensaio consiste em uma análise comparativa sobre as tradições do direito administrativo na América Latina e seus impactos no cenário contemporâneo, bem como sobre as tendências nas orientações gerais de seus sistemas de justiça administrativa. $\mathrm{O}$ método utilizado consiste em apontar as atribuições das autoridades administrativas e tentar identificar a distinção, na América Latina, entre a 'função administrativa de execução' (administrative function of implementation), o 'controle da legalidade das decisões administrativas' (não relacionada a nenhuma função jurisdicional) e a 'proteção de direitos' (por meio de uma função jurisdicional), enquanto examinamos sua gênese histórica e tendências futuras. Nessa perspectiva, o texto aborda os poderes administrativos e seus limites; as prerrogativas e instrumentos das autoridades no exercício de suas funções de aplicação; o controle das decisões administrativas pelas próprias autoridades administrativas e também por órgãos externos; bem como a proteção judicial e extrajudicial de direitos frente às decisões administrativas.

Palavras-chave: América Latina; direito comparado; justiça administrativa; tribunais. 


\section{Introducción}

Este artículo propone un análisis comparativo de los orígenes del derecho administrativo en América Latina y su impacto en el escenario contemporáneo, y presenta tendencias en las orientaciones generales de sus sistemas de justicia administrativa. El análisis se limitará a los países latinoamericanos de origen ibérico, bajo jurisdicción de la Corte Interamericana de Derechos Humanos (Corte IDH).

En este contexto, se enfatizan las atribuciones de las autoridades administrativas, y se intenta identificar la distinción, en América Latina, entre la 'función administrativa de implementación' (administrative function of implementation), el 'control de la legalidad de las decisiones administrativas' (no relacionado con función jurisdiccional alguna) y la 'protección de derechos' (a través de una función jurisdiccional), al mismo tiempo que examina su génesis histórica y prevé posibles tendencias futuras. Las funciones, que se consideran esenciales para la formación de la identidad de un modelo de justicia administrativa en América Latina, se analizarán mediante la comparación entre los sistemas jurídicos de tradición del common law y del civil law.

El artículo refleja la perspectiva sobre leyes, jurisprudencia y prácticas administrativas, lo que no siempre va al encuentro del modelo dogmático aceptado en los países latinoamericanos. Por lo tanto, se induce a nuevas reflexiones, por ejemplo, sobre la diferencia entre 'protección de derechos' y 'control de la legalidad de las decisiones', fundada principalmente en las dimensiones colectivas e individuales de las funciones administrativas de resolver conflictos y de implementar leyes (ítems 3.1 y 4.1 a 4.4). Sin embargo, esta contribución es predominantemente descriptiva desde el punto de vista del Sistema Interamericano de Derechos Humanos, el cual, de manera progresiva, se ha hecho presente en el derecho administrativo latinoamericano. Se centra especialmente en el control concentrado de las decisiones administrativas (items 4.4 y 4.5), en la atribución de poderes para resolver conflictos mediante órganos extrajudiciales (ítem 5.1) y en las decisiones de implementación sujetas a la cláusula del debido proceso (ítem 3.3) -siendo todas estas tendencias del derecho administrativo latinoamericano-. 


\section{Supuestos prospectivos para un estudio comparado}

\section{Un derecho administrativo basado en el civil law tiene como finalidad una revisión judicial típica del common law}

En América Latina, las bases sustantivas del derecho administrativo permanecen vinculadas a las raíces del derecho francés. A lo largo de los últimos 200 años, la literatura latinoamericana de derecho administrativo se ha guiado por el derecho francés y por el derecho de países originarios de este, como el derecho italiano y el alemán (Amunátegui Rivera, 1900, p. 91; Ruiz, en Harmut Maurer, 2012, p. XXXVIII). El interés de los juristas latinoamericanos por el derecho inglés y por el americano se ha focalizado en el sistema judicial, en el que la jurisdicción de los tribunales ordinarios se extiende a conflictos entre los ciudadanos y las autoridades administrativas. Este enfoque se considera más apropiado para el liberalismo (Rivero, 2004, p. 153), como contraposición al modelo francés de justice retenue, que existió antes de la reforma de 1872, y que solo fue pensado para permitir que las autoridades públicas administrativas revisaran sus propias decisiones (Lares, 1852, pp. 210-211; Uruguay, 1862, p. 178; Castillo Velasco, 1875, p. 275). Muchos de los países de origen ibérico, en América Latina, que obtuvieron su independencia a principios del siglo XIX comenzaron a adoptar el modelo constitucional de Estados Unidos (Barbosa, 1892, p. 21), especialmente su sistema judicial unificado, en el que los tribunales tienen jurisdicción tanto sobre el derecho privado como sobre el derecho administrativo. Ese sistema se constitucionalizó en Europa gracias a la Constitución belga de 1831. Entre los países que adoptaron el modelo estadounidense, donde todavía está vigente, se encuentran México, Chile, Argentina, Paraguay, Costa Rica, Perú, El Salvador, Bolivia, Brasil, Panamá, Nicaragua, Honduras y Ecuador. Los países que cuentan con tribunales generales y tribunales administrativos especializados son la excepción en América Latina: Guatemala, Colombia, República Dominicana y Uruguay (Perlingeiro, 2016, p. 160).

La gran peculiaridad del derecho latinoamericano es la coexistencia problemática de un derecho administrativo inspirado en el sistema 
jurídico del civil law y el modelo judicial inspirado en el sistema jurídico del common law.

\section{Cláusula del debido proceso administrativo y deferencia judicial}

Además, el caso Goldberg v. Kelly [397 us 254 (1970)] de la Corte Suprema de Estados Unidos confirmó que la cláusula del debido proceso era aplicable al contencioso administrativo a partir de una reinterpretación de la quinta y la décima-cuarta enmienda a la Constitución estadounidense. A raíz de esta decisión, que fue recibida con gran entusiasmo, las leyes y constituciones de los países latinoamericanos incorporaron la noción de un debido proceso legal ante autoridades administrativas (Perlingeiro, 2016, pp. 164-165).

Sin embargo, a pesar de tal previsión normativa en América Latina, no se instituyó, en favor de los funcionarios públicos investidos de poderes burocráticos decisorios, prerrogativas que apuntaran a una actuación con cierta independencia e imparcialidad, a ejemplo de los jueces de derecho administrativo (administrative law judges, $A L J$ ) estadounidenses, y tampoco se conocieron, en el derecho latinoamericano, estructuras similares a órganos administrativos con función jurisdiccional (administrative tribunals) tal como se han desarrollado en los demás países de common law, especialmente en el Reino Unido, como parte del poder judicial, y en Australia y Canadá, vinculados a un ejecutivo no político.

Por otra parte, en ausencia de una competencia especializada en derecho administrativo, los tribunales latinoamericanos tienden a tener menos expertise que los tribunales europeos, y así tienden a tratar los conflictos administrativos como si fueran conflictos de derecho privado. En palabras de Abram Chayes (1976, p. 1281), los tribunales terminan considerando más la naturaleza bilateral del conflicto (apenas la petición formulada y la defensa correspondiente) que la base estructural subyacente, cual es el interés público, que es el foco típico de una causa de derecho administrativo, incluso cuando la pretensión es traída por un individuo en frente de una agencia gubernamental.

A propósito, en el mundo del common law, los principios fundamentales del derecho administrativo sufrieron la influencia de tribunales 
ordinarios que se valieron de la analogía con los principios del derecho privado (Schwartz, 1954, p. 3).

\section{Búsqueda de una identidad propia para implementaciones, controles de decisión y soluciones de conflicto}

Como corolario lógico de tal cuadro, tribunales latinoamericanos terminaron fragmentando el deber del ejecutivo no político de asegurar la isonomía de las partes ante la ley. Las tomas de decisiones son realizadas por parte de las autoridades administrativas de conformidad con los principios de derecho administrativo basados en la ley, en las políticas públicas y en los poderes administrativos discrecionales, con énfasis en el interés público.

No obstante, los interesados a menudo se enfrentan con decisiones administrativas que no son tomadas de acuerdo con las garantías del debido procedimiento en el ámbito administrativo, ni son objeto de revisión por órganos administrativos cuasijudiciales. Tales decisiones quedan sujetas a someterse a una revisión judicial completa por parte de los tribunales ordinarios, que tienden a centrarse en la naturaleza bilateral del caso (principios de derecho privado) en lugar de considerar la base estructural del interés público (principios de derecho público).

Resulta imperioso que el derecho administrativo latinoamericano busque una identidad propia capaz de trascender su herencia europea, en razón de ciertas características de matriz francesa (actualmente con amplios poderes de revisión de las decisiones administrativas y con ausencia de autoridades cuasijudiciales) que son incompatibles con la matriz inglesa del derecho administrativo (provista de tribunales de competencia general).

El mayor desafío histórico en América Latina, en materia de derecho administrativo, ha sido establecer lineamientos que definan las competencias institucionales del poder legislativo, de los political executive, non-political executive ('the bureaucracy') y de los tribunales, en temas de creación e implementación de leyes y normas administrativas. De igual manera, establecer las competencias institucionales de la tutela jurisdiccional de derechos, sin apartarse del principio de tutela judicial efectiva, como condición para el Estado de derecho y, así mismo, definir 
las garantías del debido proceso, como base de una justicia administrativa justa y equitativa, a partir de ciertas estructuras arraigadas en sistemas legales de civil law y common law.

Reconozco que las funciones públicas decisorias serán alocadas en las funciones típicas del Estado, de acuerdo con la realidad de cada sistema jurídico (Asimow, 2015, pp. 27-28). Se trata también de incluir las nociones divergentes en derecho administrativo en cuanto a la frontera entre el derecho producido por la legislatura, por el ejecutivo político y por los tribunales, en los sistemas de civil law y de common law.

Por lo tanto, la cuestión latinoamericana reside en definir cada una de las atribuciones estatales anteriormente mencionadas y sus prerrequisitos, respetándose la evolución histórica de las bases esenciales de su derecho administrativo, de manera que la asignación de poderes en las diferentes esferas públicas decisorias no implique en la práctica la duplicidad de funciones o la ausencia de funciones.

En ese sentido, no basta con que una autoridad administrativa detenga competencia para proteger derechos: es necesario que esta reúna bases estructurales para ejercer una jurisdicción cualificada, independiente e imparcial; no basta que un tribunal se incline en producir decisiones con efectos generales, si no detiene la correspondiente legitimidad constitucional democrática; no es suficiente que un tribunal opte por la deferencia a las autoridades, cuando tales autoridades no fueran capaces de proteger derechos o de implementar normas eficazmente.

Tampoco el principio de separación de poderes es suficiente para explicar fenómenos contemporáneos, como la intensa descentralización de la estructura interna de la administración pública de Estados Unidos (Cane, 2016, p. 7; Strauss, 1984, p. 573; Pinto, 1946, p. 260). Por eso, Peter Cane prefiere hablar de "sistemas de gobierno (distribución de poder de manera difusa vs. concentrado) y regímenes de control (check-and-balance vs. accontability)" en su obra Controlling administrative power: an historical comparison (2016).

Como se observa, la dificultad para comprender la diversidad de roles de las autoridades en relación con otras esferas de poder ciertamente no es una exclusividad del derecho administrativo latinoamericano, aunque es verdad que, en los países latinoamericanos de origen ibérico, 
tal dificultad es más evidente debido a la combinación inadecuada de dos modelos jurídicos bastante complejos y distintos.

\section{Premisas prospectivas para un estudio comparado}

\section{La influencia de la Corte IDH para un nuevo derecho administrativo latinoamericano}

La jurisprudencia de la Corte IDH tiene prioridad sobre la legislación nacional en los países que se someten a su jurisdicción, y recientemente ha establecido que el control de convencionalidad es aún más amplio, involucrando a todas las autoridades estatales (ya sean órganos ejecutivos, legislativos o judiciales) [case of Expelled Dominicans and Haitians v. Dominican Republic, p. 471, Corte IDH (2014)]. Además, la implementación de leyes nacionales debe estar conforme con la interpretación que la propia Corte IDH confiere a la Convención Americana de Derechos Humanos (CADH) (llamada bloque de convencionalidad) [case of Cabrera García and Montiel Flores v. Mexico, concurring opinion of ad hoc judge Eduardo Ferrer Mac-Gregor Poisot, pp. 33-35, 37, 42, 44, 59, Corte IDH (2010)].

Una cuestión de especial interés para el derecho administrativo fue afrontada en el caso Claude Reyes y otros vs. Chile [pp. 119, 120, Corte IDH (2006)], en el cual se reconoció la implementación en parte del artículo 8.1 de la CADH a las decisiones administrativas iniciales, sometiéndolas a la cláusula del debido proceso, pero solo en lo necesario para evitar una decisión arbitraria, ya que se consideran típicas funciones administrativas de ejecución y no encierran una verdadera jurisdicción.

También vale citar que, del referido caso Claude Reyes vs. Chile, resultó la Ley Modelo Interamericana sobre Acceso a la Información Pública, aprobada por la Organización de los Estados Americanos (OEA), en la que comisiones administrativas son fomentadas y concebidas con prerrogativas de independencia para decidir sobre recursos, protegiendo derechos mediante funciones jurisdiccionales de manera similar a las agencias administrativas del administrative state (OEA, 2010). 


\section{Aproximaciones entre el derecho administrativo}

latinoamericano y el administrative state estadounidense

Como se deduce, tales perspectivas indican las tendencias del derecho administrativo latinoamericano, yendo al encuentro del principio de buena administración, consagrado en el artículo 41 de la Carta de los Derechos Fundamentales de la Unión Europea (CDFUE) y de la cláusula del debido procedimiento en el ámbito administrativo, como en el citado caso Goldberg vs. Kelly.

Se percibe también que el derecho latinoamericano se aproxima a un modelo jurídico análogo al del administrative state estadounidense con autoridades cuasiindependientes (Gordillo, 2005, pp. 955-962; Tácito, 1977, pp. 21-33), que es coherente con un sistema judicial de unidad jurisdiccional y receptivo a la deferencia judicial.

Es por ello que la presente comparación latinoamericana incluye breves exámenes del derecho administrativo de los países de common law, en particular de Estados Unidos, como fuente relevante de reflexión para el desarrollo del derecho administrativo en los países latinoamericanos que son excolonias de España y Portugal, y que se sujetan a la jurisdicción de la Corte Interamericana de Derechos Humanos, cuales son: Argentina, Bolivia, Brasil, Chile, Colombia, Costa Rica, El Salvador, Ecuador, Guatemala, Honduras, México, Nicaragua, Panamá, Paraguay, Perú, República Dominicana, Uruguay y Venezuela.

\section{Función administrativa de implementación}

\section{Dimensión individual y colectiva de las funciones de implementación}

La expresión "funciones administrativas de implementación" se refiere a las atribuciones ejecutivas típicas de las autoridades administrativas que se expresan por el ejercicio de un poder bajo dirección del interés público, alcanzando, incluso, las decisiones administrativas iniciales. 
Una de las modalidades de ejecución administrativa está dotada de una dimensión individual y se manifiesta a iniciativa del interesado, como la decisión administrativa que concede o niega una solicitud individual.

Para una mejor contextualización del tema en el derecho latinoamericano, se agrega como función de implementación otra modalidad de decisiones administrativas, cuales son las manifestaciones ex officio de las autoridades, en las que se identifica una dimensión colectiva, por ejemplo: la edición de decisiones de efecto general (incluidas las normas administrativas) y la decisión que lleva a la restricción de un derecho individual en interés de la sociedad.

Las decisiones de efecto general, incluidas por el derecho latinoamericano en el concepto de acto administrativo, no reclaman un due process previo, porque (excepto por ficción jurídica) no causan por sí solas una lesión a derechos individuales. De hecho, los actos administrativos de efecto general tienden a la abstracción y solo a través de una decisión con efecto concreto e individual se convierten en un riesgo potencial de causar daño a derechos individuales.

En el caso de una decisión que prive a una persona de derechos, la implementación administrativa se refiere únicamente a la decisión por la que se inicia el procedimiento correspondiente, que es obligatoriamente sucedida por una función de solución de conflictos para la protección de derechos, de modo que el interesado pueda defenderse en un momento posterior y antes de la decisión final.

En ese contexto, la implementación, tanto en su dimensión individual como en su dimensión colectiva, no depende de un procedimiento previo.

\section{Decisiones de los ejecutivos político y no político}

En la América Latina del siglo XIX, las decisiones administrativas con capacidad para generar efectos generales eran asociadas a actes de gouvernement, los equivalentes a las political questions estadounidenses (sobre political questions and non-reviewability, nos EUA, e non-justiciability no UK and Australia, ver Cane, 2016, pp. 489-497), que hoy son encuadradas como políticas públicas, inherentes a un poder ejecutivo político y 
a decisiones no juzgables, sobre la base de que los tribunales no poseen la experiencia y legitimidad democrática suficientes para sustituirlas.

De este modo, desde el punto de vista del derecho latinoamericano contemporáneo, se asocia la expresión poder ejecutivo no político a las decisiones administrativas individuales, es decir, a aquellas que concretizan - ante personas determinadas- normas y decisiones de efectos generales. Son las decisiones individuales, inherentes a un poder ejecutivo no político, las cuales, en principio, desafían la función pública de protección jurisdiccional de derechos; las demás, inherentes a un poder ejecutivo político, son decisiones que también se someten a control, pero de otra tipología.

Realmente, la razón por la cual una decisión de efecto general, asociada a la decisión gubernamental, puede generar responsabilidad personal de gobernante (responsabilidad administrativa, civil, penal) es el hecho de que tal decisión no tiene cómo ser movida completamente por criterios ajenos e inmunes al derecho (Mayer, 1982, pp. 3-5).

Además, el margen de discrecionalidad en la elaboración de políticas, para las autoridades encargadas de tomar las decisiones, hoy reducida por los derechos fundamentales, lleva a la conclusión de que, en una lectura actual, la expresión decisiones gubernamentales no es más que un intento de sostener que, de tal categoría de decisiones, no resulta lesión a derechos, escapándose así de la modalidad de control vía protección jurisdiccional de derechos, aunque manteniéndose otras modalidades de control, por ejemplo, un control que lleve a la responsabilidad personal de quienes toman las decisiones.

Gracias a una perspectiva flexible del derecho a una tutela judicial efectiva ( $\mathrm{CADH}$, art. 8.1), que restringe las decisiones gubernativas a solo algunos casos (e.g., a las relaciones internacionales) (Cavalcanti, 1936, pp. 37-39), el derecho latinoamericano contemporáneo ha alcanzado el extremo opuesto de la concepción extensiva de decisiones gubernamentales, que en la práctica equivalía al poder gracioso (poder discrecional) (Lares, 1852, pp. 7-8; ver Cavalcanti, 1936, pp. 140-152).

Esta concepción obsoleta de las decisiones gubernamentales, que se remonta al siglo XIX, fue estimulada por la doctrina francesa del fin político, otorgando a las autoridades inmunidad frente a los individuos (Jèze, 1928, p. 281; Cavalcanti, 1936, pp. 37-39). En ese punto, no difiere de lo 
que quedó de las doctrinas de los actes de gouvernement y de las political questions estadounidenses (Jèze, 1928, p. 275; Schwartz, 1954, p. 332).

La tendencia a exprimir el concepto de decisiones gubernamentales también se explica debido a una constante, creciente y criticable ola de judicialización por medio del control de la legalidad de las decisiones administrativas. Sin embargo, está abierto el debate sobre si las políticas públicas y otras decisiones administrativas de efecto general que, en el pasado, se escondían en el concepto amplio de decisión gubernamental están actualmente sujetas a jurisdicción. Este punto se retomará a continuación (cf. ítem 4.1 de este texto).

\section{Principio de legalidad como norte de las funciones de implementación}

El principio de legalidad administrativa en América Latina, bajo la influencia alemana, se manifiesta actualmente con su doble connotación: la primacía de la ley, afirmando que la Constitución prevalece sobre las leyes y normas administrativas; y la Grundsatz des Vorbehalts des Gesetzes, originada en el derecho prusiano (James, 1913, p. 155), según la cual la capacidad de decisión de las autoridades administrativas está limitada por la intención de los legisladores.

Por lo tanto, las decisiones de implementación administrativa en el derecho latinoamericano, antes dirigidas únicamente a la concreción de la ley en el sentido literal, hoy tienden a ser guiadas por consideraciones de constitucionalidad y de derechos o principios fundamentales, por ejemplo, el tratamiento isonómico, la seguridad jurídica y la protección de la confianza legítima.

Además, con influencia en el territorio latinoamericano, la jurisprudencia de la Corte IDH estableció que las autoridades administrativas, y no solo los tribunales, deben guiarse por la $\mathrm{CADH}$, en los términos en que la misma Corte IDH la interpreta.

En consecuencia, se imponen a los responsables de la toma de decisiones administrativas de ejecución los deberes de transparencia, publicidad, eficiencia, moralidad, así como los deberes de escuchar previamente a los interesados y motivar las decisiones, a fin de prevenir el arbitrio y hacer posible que los perjudicados impugnen las decisiones. 
Cada vez menos importancia tienen las expresiones poder discrecional y margen de apreciación, en la medida en que las elecciones a cargo de las autoridades ya no son libres dentro de una delimitación por la legislación, sino guiadas por la supremacía de los derechos humanos fundamentales, que, en caso de colisión, inducen a los tomadores de decisiones a orientarse por los criterios de proporcionalidad y del interés público preponderante.

Es perceptible, entonces, que las decisiones administrativas de implementación tienden, en la medida de lo posible, a prevenir conflictos, es decir, se anticipan a las funciones de control y de protección de derechos, según el principio fundamental del derecho a la buena administración (Carta de los Derechos Fundamentales de la Unión Europea, art. 41) y la reciente interpretación del artículo 8.1 de la CADH por la Corte IDH. Hay una tendencia a conferir a las decisiones administrativas de ejecución un carácter más efectivo, invirtiendo recursos públicos en una fase administrativa previa, sin perjuicio de revisiones posteriores (que, por lógica, serían en menor número).

\section{Prerrogativas personales $e$ institucionales en las funciones de implementación}

En efecto, las decisiones de las autoridades no están más sujetas al criterio de la estricta legalidad administrativa, sino que también deben respetar la Constitución y las convenciones internacionales. Esto genera un problema práctico: ¿cómo las instituciones administrativas y sus servidores públicos invertidos en cargos de toma de decisiones serán capaces de desafiar leyes y normas administrativas (estas editadas por órganos jerárquicamente superiores) que consideren ilegales, inconstitucionales o anticonvencionales?

¿Son las instituciones administrativas suficientemente independientes frente a otras esferas de poder e intereses económicos? ¿Están suficientemente habilitadas, son independientes e imparciales para ello?

En América Latina, los servidores públicos solían tener dificultades para defender sus propios derechos individuales (Bueno, 1857, p. 25); sin embargo, después de una reorientación gradual, ahora son generalmente reclutados a través de concursos públicos basados en expertise 
técnica y poseen posiciones estables. En consecuencia, no pierden sus empleos, a menos que sean declarados culpables de una infracción, en un procedimiento disciplinario. No obstante, muchos cargos clave para la toma de decisiones han sido ocupados por servidores públicos civiles y no civiles de carrera, dependiendo del criterio político y del grado de confianza del director de la institución, que no necesita explicar los fundamentos de su decisión; tales empleados son a menudo retirados del cargo de manera similar (Ley brasilera 8112/1990, art. 149; y Ley chilena 1/19653/2000, art. 49). En tales casos, el que ocupe un cargo esencial para la toma de decisiones carecerá de estabilidad en tal posición.

A pesar de que la ausencia de expertise viene siendo compensada por la existencia de asesores jurídicos, el hecho es que, por un lado, los dictámenes jurídicos no vinculan al tomador de decisiones; $y$, por otro, tal medida puede dejar la impresión de que quien decide, en la práctica, es el asesor jurídico que no posee la investidura para tomador de decisiones.

La ausencia de estabilidad vulnera a los funcionarios que ejercen una parte de poder, pues es una condición sine qua non para la independencia, que, a su vez, es instrumento de la imparcialidad y también de la apariencia de imparcialidad.

A propósito, la imparcialidad se hace necesaria no solo en las funciones de solución de conflictos, sino sobre todo en las funciones administrativas de implementación, porque los tomadores de decisiones de implementación, en todo momento, toman decisiones difíciles entre intereses privados e intereses públicos, de los que deben demostrar equidistancia.

Los responsables de la toma de decisiones y las instituciones administrativas necesitan demostrar independencia frente a tales intereses (independencia externa). Por ello, los responsables de la toma de decisiones deben recibir una remuneración adecuada y las instituciones deben gozar de cierta autonomía administrativa y financiera. En efecto, los funcionarios, contrariamente al ejemplo del derecho ecuatoriano (Decreto ecuatoriano 2428/2002, art. 10), necesitan independencia dentro de la propia institución a la que pertenecen, reconociéndoseles la estabilidad del cargo y las garantías de que no recibirán órdenes directas o indirectas de sus superiores jerárquicos que puedan interferir en sus convicciones para decidir (por ejemplo, garantizando la independencia interna). 


\section{Decisiones iniciales en el ejercicio de poderes que restringen derechos individuales}

Las decisiones iniciales en el ejercicio de poderes de restricción de derechos a menudo se confunden con las decisiones administrativas que solucionen conflictos, lo que es un error, ya que se someten a principios diferenciados. El acto de juzgar está rodeado de principios inherentes al debido proceso y destinado a exigir al Estado una decisión que resuelva un conflicto en el que se involucre con un interesado. Siendo así, una decisión administrativa de implementación será toda decisión administrativa que no se encuadre como una decisión de juzgar, lo que significa que una decisión de implementación no se basa necesariamente en un debido proceso legal.

En el ejercicio de los poderes administrativos sancionadores y reglamentarios, las decisiones iniciales son ejemplos de decisiones administrativas individuales de implementación: la fase inicial de indagación, en la que una comisión investiga si una persona debe ser sancionada o ser objeto de otra medida restrictiva, produce una decisión inicial según el caso. Lo mismo ocurre con el poder de las autoridades de revocar de oficio decisiones (que hayan beneficiado a alguien y) que han pasado a ser consideradas ilegales a causa de una nueva apreciación de cuestiones de hecho y de derecho. Las decisiones relativas a tales poderes son emitidas de oficio y no preceden de un debido proceso, este apenas asegurado por el deber de los juzgadores de imponer a los persecutores la carga de la prueba y de garantizar el derecho de defensa antes de cualquier decisión adversa. De este modo, durante una investigación preliminar, las autoridades no tienen ninguna obligación con respecto a los investigados, aparte de las que, en general, exigen las funciones de implementación, es decir, ninguna función de solución de conflictos está implicada.

En América Latina, la ausencia de una línea divisoria clara entre implementación y solución de conflictos, en el ejercicio de poderes administrativos que restringen derechos individuales, ha ocasionado, por una parte, el equívoco uso de la presunción de legalidad de las decisiones administrativas condenatorias, que habría de ir precedida de un auténtico debido proceso, sin el riesgo de invertir la carga de la prueba 
en detrimento del acusado; de otro lado, el equívoco de órdenes judiciales, imponiendo a las autoridades administrativas que sus decisiones iniciales sean siempre precedidas de un debido proceso, sobre la base de una lectura descontextualizada de normas legales y constitucionales que prevean el debido proceso en la fase administrativa. Como no es de la naturaleza de una decisión inicial ser precedida de un debido proceso, las autoridades no consiguen cumplir las decisiones judiciales, de modo que acaban paralizadas, y las persecuciones sancionadoras, prescritas.

\section{Decisiones administrativas iniciales que benefician a un solicitante}

Los beneficios pretendidos por los ciudadanos son conferidos por medio de una solicitud que decidirá un tomador de la decisión inicial. Este es el caso de los beneficios de la seguridad social o de los servicios de salud y de la participación en certámenes públicos destinados a vacantes en universidades y escuelas (públicas), o en empleos públicos. Como se ha explicado en precedencia, una decisión inicial, como una decisión administrativa de implementación, no precede de un debido proceso.

No obstante, en caso de que la decisión inicial por la que se examina una solicitud de beneficio cause indirectamente un perjuicio, ya sea denegando o bien concediendo la reclamación del solicitante, dicha decisión será objeto de un recurso que se resolverá mediante un procedimiento típico de las funciones jurisdiccionales. Un área gris entre implementación y solución de conflictos también se formó en los países latinoamericanos.

Solo recientemente, leyes que condicionaban la impugnación judicial a la existencia de una previa decisión inicial fueron cuestionadas en las cortes supremas, bajo el argumento de que tales leyes estarían restringiendo indebidamente el derecho constitucionalmente garantizado a una jurisdicción ante los tribunales de justicia. Este argumento se basa claramente en la falsa premisa de que una decisión administrativa inicial equivale a una decisión administrativa de solución de conflictos [RE 631.240, STF (2016)]. De hecho, si, a pesar de la previsión en ley, la solución de conflictos en sede administrativa no atiende plenamente a la cláusula del debido proceso, eso significa que otra esfera de poder de 
revisión debe estar al alcance del individuo. En general son los tribunales judiciales las que ocupan tal espacio en América Latina.

Sin embargo, una decisión inicial sobre los beneficios exigidos no puede ser sustituida por los tribunales $u$ otros órganos judiciales en ninguna circunstancia, so pena de una inversión desproporcionada de papeles institucionales: la vía judicial no sería la más adecuada, porque allí no se posee una cualificación específica para la evaluación inicial de una solicitud [Exp. 04-005845-007-CO, Res. 6866-2005, para. VIII, A, Corte Suprema de Justicia de San José de Costa Rica (2005)]. Una jurisdicción no se hará necesaria mientras los jueces detengan el poder para ordenar a las autoridades de implementación que decidan sobre la solicitud. En esa hipótesis, salvo el caso de inercia prolongada de las autoridades, que sería asimilable a la negativa de la pretensión, sería posible buscar una jurisdicción directamente y sin una previa decisión administrativa inicial [caso Biosystems SA v. Ministerio de la Salud/Hospital Posadas, Suprema Corte de la Nación Argentina (2012). Ver también artículos 200.1.2 y 201.104 de la Ley panameña 38/2000].

\section{Control de las decisiones administrativas}

\section{Dimensión colectiva del control de la legalidad versus dimensión individual de la función de solución de conflictos}

En efecto, ninguna decisión emanada por el poder público es inmune al control de legalidad (Brewer Carías, 1987, p. 9), tanto desde el punto de vista de la existencia de los hechos en que la autoridad basa su decisión como desde el punto de vista de las leyes y demás normas interpretadas y aplicadas. Sin embargo, las decisiones administrativas, desprovistas del potencial de causar automáticamente lesión a derecho individual, deben someterse a un régimen de control no jurisdiccional y proporcional a las bases de su elaboración.

La distinción que se propone entre el control de legalidad de decisión administrativa y la protección jurisdiccional de derechos reside sobre todo en sus dimensiones colectiva e individual. El control de decisiones administrativas se realiza siempre a partir de una perspectiva general, 
mientras que la protección de derechos tiene un carácter naturalmente individual. Aunque se trata de un control de decisión administrativa de efecto individual, el interés en juego no es el individual, sino el general, de la sociedad, en ver la autoridad implementar correctamente la ley y la norma administrativa.

En otras palabras, el control de las decisiones administrativas no se presta a la protección de los derechos individuales, que es comparable a un control político (Jezé, 1928, p. 246). El ejercicio del control de las decisiones administrativas, incluso de decisiones individuales, se asemeja más a una implementación (que se refiere al ejercicio ex officio de poderes administrativos, como el de autotutela - la prerrogativa de la autoridad de revisar sus propias decisiones-) que a una función jurisdiccional: en el control de las decisiones administrativas, no es un derecho individual el que está en juego, sino el interés de una colectividad. Por eso, el control de decisiones es una actuación a la que se procede ex officio, y la protección de derechos individuales es una actuación que depende de la iniciativa de los interesados. A menos que haya un conflicto intersubjetivo (conflicto entre individuos o entre individuos y entidades administrativas), en la práctica, el ente público controlador ejerce una función cuasiconsultiva o normativa, a la luz de los efectos generales de su decisión sobre la legalidad de una decisión administrativa. Lo que se quiere decir es que, si bien el control de las decisiones puede ser ejercido por los tribunales, órganos administrativos o legislativos, si no implica específicamente una lesión a los derechos individuales, dicho control, en relación con la sociedad, se caracteriza como una función pública interna corporis. La jurisdicción es una función pública imprescindible solo para la satisfacción de derechos individuales o individualizables. El debido proceso legal es una garantía del individuo contra el Estado y no al contrario, y tampoco es un poder de ciertos organismos públicos contra otros organismos públicos.

Aunque la función de proteger los derechos no deja de ser una forma de control sobre las autoridades, es una forma de control solo en un sentido indirecto. Una ilegalidad de la autoridad administrativa, reconocida en un procedimiento jurisdiccional, se considerará una presunción indirecta de la protección de derechos. Pero no siempre la premisa para reconocer un derecho individual puede o debe ser 
siempre apreciada por el juzgador; esto porque la actividad de resolver un conflicto, de naturaleza individual, no siempre se compatibiliza con la dimensión colectiva del control de decisiones administrativas.

\section{Esferas de toma de decisiones para el control de decisiones administrativas}

No se trata de sostener que falta legitimidad democrática a los tribunales o a otros órganos jurisdiccionales para regir el control de decisiones administrativas. No es mi objetivo aquí indicar qué esferas de poder y órganos serían los competentes para el control de legalidad de las autoridades. Se trata de una cuestión que corresponde a la organización política y cultural de cada Estado. En efecto, se pretende advertir que un régimen de control sobre la legalidad de las decisiones no se convierte en jurisdiccional únicamente por el hecho de ser de competencia de un tribunal (Nunes, 1943, p. 5), y que el factor determinante en la jurisdicción es el derecho del individuo, siendo misión preponderante de un juzgador la protección de derechos, y no el control de legalidad de las decisiones administrativas. Frente a ese mismo panorama también está en juego la credibilidad de la que goza cada una de las esferas de poder o del ente administrativo en una sociedad. No se ignora que, en países con autoridades desacreditadas y desestructuradas, la atribución de una competencia a los tribunales para decidir sobre el control de legalidad de las decisiones administrativas puede ser una necesidad.

En Brasil, la ação de improbidade administrativa es un ejemplo de que el legislador, no confiando plenamente en las autoridades para el ejercicio del poder sancionador disciplinario, creó un proceso judicial de iniciativa del Ministerio Público con el mismo efecto (Ley brasilera $8429 / 1992$, art. $1^{\circ}$ ). Esto significa que la importancia relativa de los papeles representados por los tribunales, en una sociedad determinada, depende de la credibilidad de las demás esferas de poder (Strauss, 2016, pp. 430-431, n. 89).

A propósito, se observa un aumento en el número de leyes relativas a las acciones populares (actio popularis) (Constitución brasilera de 1988, art. 5.73; Ley costarricense 8508/2006, arts. 10.1.d y 10.2; y Ley colombiana 1437/2011, arts. 135 y 137. Sobre el surgimiento de 
la acción popular en Brasil, ver Fagundes, 1946, pp. 1-19). Se trata de demandas judiciales relacionadas con cuestiones administrativas en las que cualquier ciudadano tiene capacidad para demandar, aunque no esté directamente interesado en el objeto de la controversia, ya que tales acciones se basan más bien vagamente en un sistema democrático de participación directa (sobre la participación popular, credibilidad de instituciones y regímenes dictatoriales, ver Friedrich, 1941, pp. 536-563).

Pero, aunque resulte comprensible, esta inversión de papeles no siempre es proporcional y puede ocasionar una disfunción institucional. El coste de aceptar decisiones jurisdiccionales que no sean democráticas ni igualitarias puede ser muy alto (Mashaw, 2005, pp. 167-168). Por otra parte, los legisladores deberían abstenerse de atribuir cuestiones no justiciables a los tribunales o a los órganos cuasijudiciales, es decir, deberían abstenerse de otorgarles atribuciones sobre cuestiones que un juzgador no sea cualificado para resolver, sin una expertise técnica adicional y sin legitimidad democrática (presupuestos típicos de deferencia judicial).

\section{Parámetros procedimentales para el control de legalidad administrativa}

Permitir que los tribunales y los órganos jurisdiccionales decidan sobre cuestiones administrativas de efecto general, incluso cuando son incluidas como fundamento de una pretensión individual (Ley argentina 19549/1972, art. 24.a; Ley costarricense 8508/2006, art. 36.3; Ley colombiana 1403/2011, art. 138.2; Ley hondureña 152-87/1987, art. 129; y Ley hondureña 189-87/1988, art. 30), es una invitación a que los tribunales y los jueces en general hagan política o interfieran en las políticas públicas, mediante un procedimiento cuestionable.

La función ejercida por los órganos jueces acerca de las pretensiones que están primordialmente dirigidas contra leyes o acciones administrativas de efecto general es una actuación que, al revés de aferrarse solamente a principios adscritos a la tutela judicial efectiva, debe acercarse, en la medida de lo posible, a los principios democráticos que guían las esferas de poder destinadas a la creación de leyes y normas administrativas. 
Esto incluye el ejercicio de un margen de discrecionalidad para la elaboración de políticas que involucren opciones difíciles, por ejemplo, asignaciones presupuestarias.

La efectividad del control de una decisión administrativa de alcance general depende de la expertise y sobre todo de la aptitud democrática del tomador de decisiones que ejerce el control. Además, es necesario un procedimiento adecuado para garantizar que la decisión resultante surta los efectos generales correspondientes (Perlingeiro, 2007, pp. 255272). Por lo tanto, los argumentos de las partes y de los jueces en un procedimiento jurisdiccional tradicional no serían determinantes hasta que no tuviesen -las partes y los jueces - una legitimidad suficiente para vincular a la colectividad.

La dimensión colectiva del control de las decisiones incluye las repercusiones y los efectos indirectos en la sociedad de una decisión administrativa inicialmente dirigida a personas determinadas. Tales decisiones desafían, en la óptica del individuo perjudicado, la función pública de protección de derechos, mediante jurisdicción, pero, desde el punto de vista de los terceros indirectamente afectados, no pasan de un control de decisiones administrativas de efecto general.

Tratándose de una decisión administrativa individual, es importante que se diga que el control debe ser siempre contra organismos públicos y nunca contra individuos, aunque la decisión bajo control les favorezca.

$\mathrm{Si}$, como consecuencia de un control, el órgano controlador indica que la esfera de algún derecho individual puede ser alcanzada, corresponde a la autoridad inicial o al propio órgano controlador propiciar al interesado un debido proceso (derecho a la jurisdicción). En tales situaciones, la decisión de control será definitiva para la autoridad controlada, pero equivalente a una decisión inicial ante el individuo perjudicado.

\section{Control concentrado para cuestiones administrativas de efecto general}

Los sistemas jurídicos que adoptan un control concentrado de constitucionalidad de leyes y un control concentrado de legalidad de normas administrativas más se afinan con la noción de que el control de 
normas administrativas se somete a un procedimiento diferenciado en relación con la jurisdicción (González Pérez \& Cassagne, 2005, p. 55).

De hecho, hay una incompatibilidad procedimental en mantener en el mismo proceso y ante el mismo órgano decisorio dos medios de control esencialmente diferentes (con fundamento distinto, aunque en la misma dirección, Cassagne, 2003, pp. 124-125. Ver también artículo 20 del Euro-American Model Code of Administrative Jurisdiction, 2014): la protección de derechos con su dimensión individual vía función jurisdiccional y el control de decisiones con su dimensión colectiva y naturaleza de función de implementación. En ese contexto, hay interesantes ejemplos en los derechos panameño, dominicano y nicaragüense -Ley panameña 135/1943 (procedimiento gubernativo), arts. 29-42; Ley nicaragüense 350/2000, arts. 17.1-2 y 35-45; y Ley dominicana 1.494/1947, art. 7.a-b)-.

Además, permitir que una demanda individual basada principalmente en una cuestión de interés general (validez de ley y de norma administrativa) pueda ser decidida solo en favor del demandante individual, lo que es de la naturaleza de una función jurisdiccional, es fragmentar el derecho administrativo en dos: uno frente a los demandantes y otro frente a los no demandantes, por lo que, en opinión del autor, los jueces no deberían prestarse para asumir un papel de dicha naturaleza.

\section{Tendencias extraídas del control de convencionalidad por las autoridades}

Una nueva luz sobre el tema fue traída por la Corte IDH, que partió de la premisa de que, si las autoridades administrativas de implementación y de solución de conflictos no detienen, de acuerdo con la legislación de sus Estados, poder para ejercer control de constitucionalidad, tampoco tendrían para el ejercicio pleno del control de convencionalidad, es decir, no tendrían cómo dejar de implementar una ley nacional bajo el fundamento de que ella es anticonvencional. En esta hipótesis, según la Corte IDH, las autoridades suscitarían un incidente sobre la convencionalidad ante el órgano competente para decidir sobre el control de constitucionalidad [case of Cabrera García and Montiel Flores v. Mexico, voto do juiz ad hoc Eduardo Ferrer Mac-Gregor Poisot, pp. 37, 39, 
I/A Court HR (2010)]: "Un término medio entre un control difuso absoluto y un control concentrado" (Ramírez, 2015, p. 145, n. 139).

En países que adoptan un régimen de control de constitucionalidad concentrado, como en Europa continental, tal providencia pasaría desapercibida, pues la tesis de la Corte IDH es bastante coherente con tal sistema.

Pero en América Latina, en los países que adoptan un régimen de control judicial difuso de constitucionalidad, por influencia del constitucionalismo estadounidense, las autoridades administrativas encargadas de la aplicación y la solución de conflictos se ven abocadas a la falta de competencia para decidir sobre una cuestión constitucional o convencional que afronte la legislación nacional, de modo que deben esperar la decisión de un órgano judicial de control constitucional. Sin embargo, en general, cualquier órgano judicial puede desde luego decidir cualquier cuestión constitucional o convencional, lo que estimula las demandas judiciales y abre la oportunidad para fragmentar aún más el derecho administrativo.

Por lo tanto, se espera que el incidente de anticonvencionalidad que suscitarán las autoridades sirva de referencia para que se establezca en el derecho administrativo latinoamericano un incidente de legalidad y constitucionalidad (en relación con las cuestiones administrativas de efecto general) en el ámbito administrativo y judicial.

\section{Protección de los derechos ante las autoridades administrativas y los tribunales (mediante la vía de la jurisdicción)}

\section{Equilibrio entre la solución de conflictos ante}

\section{las autoridades administrativas y ante los tribunales}

La protección de derechos a través de la jurisdicción es una atribución típica, mas no exclusiva, de los tribunales. Entiéndase derecho a la jurisdicción como un derecho humano fundamental, con base en el artículo $8^{\circ}$ del CADH - de conformidad con el artículo $6^{\circ}$ del Convenio Europeo de Derechos Humanos (CEDH) y con el artículo 14 del 
Pacto Internacional de Derechos Civiles y Políticos (PIDCP)-, y una vez cumplidas las condiciones establecidas por dichas normas, la función desempeñada será considerada legítima, independientemente de la esfera de poder estatal que la constituya.

Sin embargo, admitir la asignación de la jurisdicción en cualquiera de las esferas de poder no significa autorizarla simultáneamente en más de una esfera. Esto supondría una duplicidad de recursos públicos para un mismo fin y un debilitamiento de la seguridad jurídica, con retraso en la solución del conflicto.

En el caso de organismos públicos comprometidos en la protección de los derechos individuales contra las decisiones administrativas de implementación, su función de resolver conflictos adquiere una gran credibilidad, en la medida en que los juzgadores administrativos demuestren ser cualificados, independientes e imparciales (Gordillo, 2013, pp. X-14). No obstante la etiqueta de solución de conflictos, jurisdicción o protección de derechos que se atribuya a una función pública, en ausencia de los pilares de expertise, independencia e imparcialidad, esta podrá caracterizarse como una función de implementación o como una decisión cuasijudicial y, en tales casos, deberá ser suministrada posterior y proporcionalmente por otra esfera de poder. De cierta forma, es lo que sucede con la doctrina de la deferencia judicial, facilitada por la existencia de órganos casi independientes, como los ALJ en Estados Unidos, que deciden sobre cuestiones de hecho en las agencias administrativas, mientras que los tribunales tienden a decidir solamente sobre otros puntos de la pretensión. Este enfoque evita la redundancia y la duplicidad de funciones destinadas a la solución de conflictos.

En otras palabras, en un sistema jurídico en el que los tribunales tienen la última palabra sobre la protección de los derechos individuales, cuanto mayor sea la deferencia que estas nutren por las autoridades administrativas que deciden los conflictos, mayor es el signo de que tales autoridades ejercen con eficacia sus funciones semejantes a la jurisdicción. Y viceversa: cuanto más frágil sea el debido proceso garantizado por dichas autoridades, menor será la deferencia que los tribunales podrán ofrecerles y más intensa será la revisión judicial sobre las decisiones administrativas. El quantum de deferencia judicial, por lo tanto, actúa como un medidor de competencia, independencia e imparcialidad de 
un órgano público destinado a la protección de derechos mediante una actuación de resolución de conflictos (Cane, 2016, p. 268). En ese contexto, la doctrina del agotamiento de los remedios administrativos, por ejemplo, el acto de condicionar el acceso a un tribunal (competente, independiente e imparcial) a la realización de un previo proceso en la esfera administrativa será justificable solamente en cuanto el individuo no corra el riesgo de verse privado de las garantías de un debido proceso en la esfera administrativa. Tal y como se explica en el ítem 5.2 de este ensayo, en América Latina este riesgo es real.

\section{La protección (in) efectiva de derechos en el ámbito de la administración pública}

La jurisdicción otorgada por el Estado es un derecho humano fundamental que depende principalmente de la presencia de jueces competentes, independientes e imparciales. Sin embargo, en América Latina, la jurisdicción es una actividad ejercida prevalentemente por tribunales no especializadas en derecho administrativo. Con raras excepciones, en América Latina no existen instituciones administrativas jurisdiccionales que cumplan los tres criterios, es decir que sean competentes, independientes e imparciales.

A pesar de que el sistema judicial latinoamericano tiene rasgos del derecho estadounidense, pocas leyes conocen estructuras como la de los ALJ estadounidenses y la de los tribunals administrativos canadienses y australianos que integran el poder ejecutivo. Los pocos ejemplos de órganos cuasijudiciales latinoamericanos, junto con el tribunal marítimo brasilero [Agravo de Instrumento 11094, $2^{a}$ turma, STF (1934); Agravo de Instrumento 62811, $1^{\text {a }}$ turma, STF (1973)], se refieren al derecho de acceso a la información oficial, respaldados por la Ley Modelo Interamericana sobre Acceso a la Información Pública. Tales órganos cuasijudiciales, en materia de derecho a la información, pueden encontrarse en Chile, El Salvador, Honduras y México (Perlingeiro, 2018, p. 115).

En general, los procedimientos latinoamericanos en sede administrativa, a pesar de tener el objetivo de solucionar conflictos y de brindar a los interesados la oportunidad de manifestarse, no inducen jurisdicción; estos son, en esencia, funciones administrativas de implementación, y 
se someten a una revisión judicial completa. No acaso, en el derecho español y portugués (en italiano también), hay una distinción entre proceso y procedimiento: el término proceso designa la actividad de jurisdicción llevada a cabo por autoridades o jueces independientes e imparciales; distintamente, procedimiento se refiere a una actividad que solo tiene apariencia de jurisdicción, porque, de hecho, está dirigida por autoridades sin prerrogativas de independencia.

Sin embargo, en América Latina, los procedimientos en la esfera administrativa no garantizan realmente un proceso justo, que es una disposición exclusiva de los tribunales de competencia común, dando como resultado una serie de consecuencias jurídicas que no han sido, hasta el momento, claramente asimiladas por el derecho administrativo de los países latinoamericanos.

Con base en la Constitución y en las leyes, las personas reclaman el derecho a un debido proceso ante las autoridades administrativas, en particular para defenderse de los poderes administrativos sancionadores y reglamentarios, que tienen por objeto la restricción de derechos. Como las autoridades nacionales latinoamericanas no son capaces de ofrecer las garantías de un debido proceso, como la audiencia por un órgano juzgador competente, independiente e imparcial, previamente establecido por la ley, el resultado práctico es que las demandas se trasladan ante los tribunales para la decisión plena y definitiva sobre dichos poderes administrativos; es decir, los poderes sancionadores y reglamentarios, cuando, resistidos por los interesados, son enteramente conducidos por los tribunales.

Un escenario similar ocurre con las pretensiones que buscan algún beneficio público, a partir de requerimientos. Si la solicitud es denegada por una decisión inicial, las leyes suelen prever un recurso de reconsideración ante el mismo tomador de la decisión, así como un recurso ante un órgano jerárquicamente superior. No obstante, en la práctica, los interesados buscan directamente los tribunales, en la medida en que, sabiendo de la ausencia de juzgadores independientes o casi independientes en campo administrativo, intentan la suerte directamente en la única esfera de poder que puede ofrecer una jurisdicción efectiva. 


\section{La protección (ilusoria) de derechos en campo judicial ante los tribunales}

En los últimos años, los tribunales latinoamericanos han desempeñado un protagonismo desenfrenado en el derecho administrativo, con papeles que desbordan la protección de derechos y conforman, ante los demandantes, un derecho administrativo diferenciado. Tal desenvoltura para el activismo no es una exclusividad del derecho latinoamericano, considerado en ciertas circunstancias un problema general, incluso para los sistemas de justicia administrativa que priman por una revisión judicial cerrada. Me refiero a la inmunidad de los jueces que les exime de la responsabilidad que por regla general tienen las autoridades en el ejercicio de sus competencias de implementación (Strauss, 2016, p. 455).

Pero la peculiaridad latinoamericana está en la ausencia de un proceso jurisdiccional efectivo, en la fase administrativa, asociada a la existencia de tribunales no especializados en derecho administrativo, como única alternativa a una función jurisdiccional en materia de derecho administrativo. Además, una conjunción de factores que agravan el marco antes citado exige una urgente reflexión en el derecho latinoamericano:

- La falta de confianza de los juzgadores en relación con las autoridades de implementación, que tampoco despiertan en la sociedad mayor credibilidad de lo que despiertan en los tribunales, especialmente porque las autoridades administrativas latinoamericanas y los servidores públicos carecen de las prerrogativas necesarias para actuar con independencia.

- Un régimen de control de constitucionalidad difuso ante los tribunales, que conspira para un control difuso de la legalidad de normas administrativas y que atribuye a los tribunales el poder de decisión sobre los aspectos individuales de una pretensión, y también en el mismo proceso, incidentalmente, el poder de decidir sobre los fundamentos de índole colectiva de tal pretensión.

- Decisiones judiciales sobre las pretensiones individuales que enfrentan, como fundamento, cuestiones de naturaleza general (leyes y normas administrativas), de un lado, produciendo efectos inter partes 
y, por eso, criticadas por servir de instrumento de ruptura del deber de igualdad de la administración pública; y, por el otro, generando efectos erga omnes sin suficiente legitimidad democrática.

En ese escenario, los tribunales son instadas por la sociedad a tener superpoderes, haciendo creer a sus miembros que realmente los tienen (Vianna, Carvalho \& Burgos, 2019, pp. 136-145). Los tribunales son aplaudidos por los medios de comunicación por abordar cuestiones extremadamente controvertidas, desde el punto de vista de un conflicto individual hasta el punto en el cual sus miembros son calificados de valientes dispensadores de justicia, que resulta negada por las autoridades viles. Sin embargo, tales decisiones son ilusorias, pues así proceden los tribunales en detrimento del escrutinio de las bases estructurales (de dimensión colectiva) y determinantes del conflicto intersubjetivo, bases estas envueltas en políticas públicas, fijadas por leyes y normas administrativas, que son solo parcialmente consideradas. En consecuencia, cuando las decisiones judiciales no son inviables, se comprometen innumerables derechos fundamentales, que se hacen desapercibidos en tal jurisdicción disfuncional.

\section{Conclusiones}

Los papeles institucionales básicos de poder se mantendrán más fácilmente si los órganos tomadores de decisiones iniciales adquieren a los ojos de la sociedad la expertise administrativa necesaria y la legitimidad democrática. Esto conduciría a un sistema de justicia administrativa más justo y equitativo. En una relectura sobre los regímenes de control y distribución de poderes, ajustada a las realidades latinoamericanas, especialmente a la brasilera, se concibe el ejercicio eficaz de las funciones decisorias de implementación, control de legalidad de decisiones administrativas y de protección (jurisdiccional) de derechos, independientemente de sus asignaciones en las ramas tradicionales de poder del Estado.

Por cierto, no son necesariamente los tribunales y otros órganos jurisdiccionales los más cualificados y dotados de legitimidad democrática 
para, bajo el pretexto de proteger derechos, ejercer incidental y simultáneamente el poder de revisión (control de legalidad) sobre las demás instituciones del Estado. No está en juego la legitimidad de un tribunal en crear derechos o actuar con activismo, el punto en cuestión es que un tribunal o cualquier otro órgano jurisdiccional no deberían poder crear normas abstractas, con efecto erga omnes, sobre una cuestión administrativa de alcance general, a partir de un caso concreto, sin que detengan legitimidad y expertise adecuadas. Estas tampoco deben utilizarse como instrumento de ruptura del principio de isonomía en el derecho administrativo, instituyendo en la práctica normas cuyo efecto se limita específicamente a los demandantes.

A lo largo de la historia, se han instituido estructuras de poder basadas en la aptitud que poseen para determinadas funciones:

- Las funciones de implementar la ley y la de controlar la implementación de leyes deben ser ejercidas por órganos dotados de expertise (sobre todo en lo que se refiere a decisiones individuales) y de legitimidad democrática (sobre todo en lo que se refiere a decisiones de efecto general).

- La función de proteger los derechos requiere expertise, independencia e imparcialidad de los juzgadores en relación con los tomadores de la decisión impugnada.

Es a partir de tales aptitudes que se distribuyen los papeles institucionales en las distintas esferas de poder y se aleja el riesgo de incurrir en lagunas o redundancias en el ejercicio de dichos papeles.

Esta ecuación no debe ser adulterada, so pena de distorsión del sistema jurídico.

Además, existe una verdadera distinción entre los procedimientos de protección de derechos y los de control de decisiones: las bases procesales correspondientes deben tener relación con el carácter sustancial del derecho a ser protegido y de la decisión a ser controlada. De hecho, los juzgadores se orientan por la cláusula del debido proceso legal y persiguen la reparación del derecho abusado a través de una decisión administrativa individual. Si bien los controladores se valen de un procedimiento similar que lleva a la creación de una decisión 
controlada y que, de esta forma, no se sujeta necesariamente a un debido proceso, lo que aquí sería considerado una ficción jurídica, en la medida en que el control de decisión administrativa no pasa de una decisión de implementación de nivel superior.

A propósito, mientras que la protección de derechos está dirigida hacia la satisfacción del interés individual, con efecto inter partes, el control de decisiones administrativas está dirigido a salvaguardar el interés público, con efecto erga omnes. No se debe tratar de alterar la naturaleza de las cosas.

De este modo, el poder de interpretar la ley por los jueces en derecho administrativo encuentra límites en las barreras individuales del conflicto que debe ser solucionado. Si, de la interpretación de la ley por el juez, los terceros pudieran ser beneficiados o perjudicados, es porque el juzgador puede estar invadiendo la competencia de otros tomadores de decisiones, siendo cierto que la cuestión debe ser blanco de un control abstracto, y no de una jurisdicción.

La interpretación del juez que vacía el contenido de una ley o norma administrativa y que suple la omisión de una ley o norma es una acción que equivale a la anulación o a la creación de una norma, mereciendo, por lo tanto, ser de competencia de un órgano con la naturaleza apropiada y no de un juzgador. En este contexto, lo ideal sería concentrar la competencia en un único órgano dotado de las aptitudes necesarias para decidir sobre cuestiones administrativas de interés general. Un procedimiento de competencia difusa para el control de la legalidad administrativa en general presupone la posibilidad de una pluralidad de órganos decidiendo simultánea y contradictoriamente sobre el mismo asunto, por ende, solo es compatible con la protección jurisdiccional de derechos individuales.

En consecuencia, se pone en jaque, en América Latina, el control difuso de constitucionalidad de leyes ante los órganos jurisdiccionales, de origen estadounidense, que indirectamente es un incentivo al control difuso, con efecto concreto, de normas administrativas ante cualquier órgano judicial. La idea de separación entre la protección de derechos y el control de decisiones administrativas encuentra paralelo en el régimen de constitucionalidad concentrado, como está configurado actualmente en la Europa continental. 
Por último, aunque sea evidente, pero quizá poco recordado y reflexionado, vale la pena señalar que, cuanto más los ciudadanos sientan que las autoridades ejecutivas (de implementación de leyes) están respetando los derechos fundamentales y las garantías constitucionales, menos ellos recurrirán a los órganos juzgadores, controladores y revisores de decisiones iniciales. Como es mejor evitar los conflictos con medidas prospectivas que remediarlos con medidas retrospectivas, es pertinente que los tomadores de decisiones de implementación estén dotados de prerrogativas similares a las que poseen las autoridades juzgadoras controladoras.

El aspecto negativo en el futuro del derecho administrativo latinoamericano es la ausencia de signos indicativos de que los tribunales, especialmente en demandas individuales, dejarán de ser competentes para decidir sobre pretensiones de índole estructural de las autoridades escrutadas. Por lo tanto, existe todavía un riesgo de disfunción de los papeles institucionales básicos. Sin embargo, el lado positivo es que, bajo la jurisprudencia de la Corte IDH, el derecho administrativo latinoamericano tiende a transferir a las autoridades administrativas parte del poder de solución de los conflictos y tiende a conferir a las autoridades de implementación garantías para la toma de decisiones con mayor respeto a los derechos fundamentales. Esto debe reducir el papel representado por los tribunales ordinarios y prevenir conflictos ante los órganos de decisión de causas administrativas.

Así mismo, según la jurisprudencia de la Corte IDH, las autoridades administrativas con funciones de implementación y de resolución de conflictos no tienen competencia para un control de convencionalidad pleno, debiendo ser este ejercido de manera concentrada ante los órganos judiciales nacionales competentes para el control de constitucionalidad.

Tal visión puede ser una orientación en América Latina, llevando a un futuro control concentrado de normas y de decisiones administrativas de efecto general, incluso las relacionadas con demandas individuales, mediante la instauración de un incidente de legalidad o de constitucionalidad de normas. De esta manera, resultaría en una separación formal entre la protección jurisdiccional de derechos y el control de decisiones administrativas. 
En síntesis, un modelo de justicia administrativa para América Latina que anhele un derecho administrativo justo y equitativo debe: a) basarse en el control de decisiones administrativas, inspirado en el control concentrado de normas europeas; b) estar asociado a un sistema jurisdiccional de protección de derechos descentralizado, independientemente de la rama de poder en la que esté asignado, típicamente estadounidense; y c) también estar asociado a un sistema de decisiones administrativas de implementación que se sujeta, en la medida de lo posible, a la primacía de los derechos fundamentales, tal y como consta en el orden jurídico internacional de derechos humanos.

\section{Referencias}

Amunátegui Rivera, J. D. (1900). Resumen de derecho administrativo aplicado a la legislación de Chile. Santiago de Chile: La Razón.

Asimow, M. (2015). Five models of administrative adjudication. The American Journal of Comparative Law, 63(1), 3-32.

Barbosa, R. (1892). Habeas corpus. Bahia, Brasil: Typographia do Diario da Bahia. Brewer Carías, A. R. (1987). Estado de derecho y control judicial. Madrid: Instituto Nacional de Administración Pública.

Bueno, J. A. P. (1857). Direito público brazileiro. Rio de Janeiro: Typographia imp. e const. de J. Villeneuve E. C.

Cane, P. (2016). Controlling administrative power: an historical comparison. Cambridge: Cambridge University Press.

Cassagne, J. C. (2003). Perspectivas de la justicia contencioso-administrativa en Argentina en el siglo XXI. En M. J. M. Chiner (Ed.), La justicia administrativa (pp. 117-134). Barcelona: Atelier Libros.

Castillo Velasco, J. M. del. (1875). Ensayo sobre el derecho administrativo mexicano, 2. México: Castilho Velasco e Hijos.

Cavalcanti, T. B. (1936). Instituições de direito administrativo brasileiro. 2. Rio de Janeiro: Livraria Editora Freitas Bastos.

Chayes, A. (1976). The role of the judge in public law litigation. Harvard Law Review, 89(7), 1281-1316.

Fagundes, S. M. (1946). Da ação popular. Revista de Direito Administrativo, 6, 1-19.

Friedrich, C. J. (1941). Constitutional government and democracy: theory and practice in Europe and America. Boston: Little, Brown \& Co. 
González Pérez, J., \& Cassagne, J. C. (2005). La justicia administrativa en Iberoamérica. Buenos Aires: Abeledo Perrot.

Gordillo, A. (2005). Los tribunales administrativos como alternativa a la organización administrativa. RAP, 955-962.

Gordillo, A. (2013). Tratado de derecho administrativo y obras selectas. Tomo 1. Buenos Aires: FDA.

James, H. G. (1913). Principles of Prussian administration. New York: Macmillan Company.

Jèze, G. (1928). Los principios generales del derecho administrativo. Madrid: Reus. Lares, T. (1852). Lecciones de derecho administrativo. México: Imprenta de Ignácio Cumplido.

Mashaw, J. L. (2005). Judicial review of administrative action: reflections on balancing political, managerial and legal accountability. Direito GV Law Review, 153-170.

Maurer, H. (2012). Derecho administrativo alemán. México: Universidad Nacional Autónoma de México.

Mayer, O. (1982). Derecho administrativo alemán. 1. Buenos Aires: Depalma.

Nunes, C. (1943). Do poder judiciário. Rio de Janeiro: Revista Forense.

Organización de los Estados Americanos (OEA). (2010). AG/RES. 2607 (XL0/10). Ley Modelo Interamericana sobre Acceso a la Información Pública.

Perlingeiro, R. (2007). A impugnação judicial de atos administrativos na defesa de interesses difuso, coletivo e individuais homogêneos. Revista de Direito do Estado, 7, 255-272.

Perlingeiro, R. (2016). Perspectiva histórica de la jurisdicción administrativa en América Latina: tradición europea continental versus influencia estadounidense. Revista de Derecho Administrativo, 103, 141-174.

Perlingeiro, R. (2018). Principals of the right of access to information in Latin America. En H.-J. Blanke \& R. Perlingeiro (Eds.), The right of access to public information: an international comparative legal survey (pp. 71-130). Berlin: Springer.

Perlingeiro, R., \& Sommermann, K.-P. (2014). Euro-American model code of administrative jurisdiction. Niterói, Brasil: Editora da UFF.

Pinto, B. (1946). Separação de poderes. Revista de Direito Administrativo, 6, 243-275.

Ramírez, S. G. (2015). The relationship between Inter-American jurisdiction and states (national systems): some pertinent questions. Notre Dame Journal of International \& Comparative Law, 5(1), 115-151. 
Rivero, J. (2004). Curso de direito administrativo comparado. São Paulo: Revista dos Tribunais.

Schwartz, B. (1954). French administrative law and the common-law world. New York: New York University Press.

Strauss, P. L. (1984). The place of agencies in government: separation of powers and the fourth branch. Columbia Law Review, 84(3), 573-669.

Strauss, P. L. (2016). An introduction to administrative justice in United States. North Carolina: Carolina Academic Press.

Tácito, C. (1977). Presença norte-americana no direito administrativo brasileiro. Revista de Direito Administrativo, 129, 21-33.

Uruguay, V. (1862). Ensaio sobre o direito administrativo. Rio de Janeiro: Typographia Nacional.

Vianna, L. W., Carvalho, M. A. R., E Burgos, M. B. (2019). Quem somos: $a$ magistratura que queremos. Brasília: Associação dos Magistrados Brasileiros (AMB). 